\title{
Kuatkan Etika Terhadap Lingkungan ${ }^{1}$
}

Oleh Gede H. Cahyana

Koran Bandung Ekspres, 3 Juni 2011

Organisasi Kesehatan Dunia (WHO) merilis data sbb: sekitar 200 juta orang tidak memiliki sumber air bersih yang layak diminum, 350 juta orang tidak punya fasilitas sanitasi dasar yang sangat dibutuhkan, dan satu milyar orang tidak punya sistem pengelolaan sampah. Buruknya sanitasi dan penyediaan air minum itu meningkatkan kematian bayi/anak dan mengurangi umur harapan hidup. Data lain menyebutkan 1,3 milyar orang hidup tanpa air bersih dan 2 milyar tanpa sanitasi dasar (air limbah dan sampah). Bagaimana di Indonesia? Bagaimana di Kota Bandung?

Bagai gelindingan bola salju, isu lingkungan terus membesar dan meluas. Agamaagama besar di dunia sejak Deklarasi Stockholm pada Juni 1972 diarahkan untuk membantu menopang kesadaran pelestarian fungsi lingkungan melalui eksplorasi ajarannya. Ajaran agama dianggap mampu memperkuat kesadaran manusia untuk melestarikan fungsi lingkungan dan memperkaya konsep hukum kesinambungan ekologi. Selain peraturan, hukum dan undang-undang sekuler, juga perlu kesadaran otentik dari relung batin manusia berupa nilai-nilai etika, moral, akhlak menurut agama. Agama tidak hanya berkutat pada hal-hal spiritual transenden tetapi juga beranjak ke aspek riil pemeluknya. Dengan nilai-nilai etika manusia akan memiliki kemampuan untuk mengatasi masalahnya tanpa merusak keharmonisan dengan lingkungan.

Telah tampak kerusakan (lingkungan) di darat dan laut karena ulah manusia. (Ar Ruum: 41)

"Krisis lingkungan terjadi bukan karena pengembangan sains dan teknologi, melainkan hasil dari sikap mental dan moral manusia serta life-style dunia modern", kata E.F. Schumacher.

Dua kutipan di atas merujuk pada satu materi yang sama, yaitu Bumi dalam arti lingkungan, atau lebih khusus lagi ialah darat (termasuk udara) dan laut. Rujukan itu pun menegaskan kaitan antara komponen lingkungan abiotis: air, tanah (Bumi) dan biotis (makhluk hidup) yang merangkaikan tiga mata rantai peringatan, yaitu Hari Air (22 Maret), Hari Bumi (22 April), dan Hari Lingkungan (5 Juni). Berbicara tentang lingkungan berarti bicara tentang tiga komponen utama Bumi, yaitu tanah, air dan udara. Ketiganya tak dapat dipisahkan dari hidup manusia dan memiliki relasi timbal balik dengan manusia.

Tanah (Bumi) penting, air penting, udara juga penting. Ketiganya menjadi kekuatan bagi makhluk hidup karena sangat bernilai. Kata "nilai" atau value air misalnya, menurut Vandahana Shiva, berasal dari bahasa Latin valere yang artinya "menjadi kuat atau patut". Air adalah kekuatan bagi makhluk hidup. Orang dan binatang akan

\footnotetext{
${ }^{1}$ Disampaikan dalam Seminar Nasional: The Smiling Earth, Jurusan Teknik Lingkungan, Universitas Kebangsaan, Bandung, Sabtu, 28 Mei 2011.
} 
mencarinya ke mana saja, di mana saja dan dengan kekuatan apa saja, termasuk kekuatan senjata alias perang. Film Water World yang dibintangi Kevin Kostner berintikan perjuangan merebut tanah dan air tawar. Begitu besar kekuatan air dan tanah (udara) itu sampai-sampai di tatar Sunda, Jawa Barat ada kata-kata hikmah: leuweung ruksak - cai beak - manusa balangsak, hutan hilang - air habis - manusia menderita.

Selain di tatar Sunda, kearifan lokal yang dapat melestarikan fungsi lingkungan air, tanah, dan udara juga dimiliki oleh komunitas masyarakat lain. Tradisi ujung ladang masyarakat Melayu Sumatera Utara misalnya, selalu berwawasan lingkungan kalau akan membuka hutan. Meski menebang pohon dan membabatnya, selalu ada vegetasi pelindung yang tersisa. Pola seperti ini membantu menahan tanah agar tidak erosi atau merusak tanaman. Begitu juga Suku Dayak di Kalimantan, mereka punya tradisi Nyaang. Mereka biasa membuat lajur isolasi pada ladang atau ketika membabat hutan untuk melokalisir kebakaran. Yang lainnya, awig-awig di Bali yang melarang menebang pohon (biasanya pohon bunut atau beringin). Kemudian, tradisi sasi di Saparua Maluku berlaku di darat atau di laut atas komoditas yang haram dieksploitasi untuk waktu terbatas. Semuanya adalah kearifan tradisional masyarakat yang sering dianggap awam atau ketinggalan zaman oleh orang kota yang justru sebagai perusak lingkungan.

Tampak bahwa kerusakan lingkungan, krisis air, tanah kritis, dan polusi udara terjadi karena perilaku manusia telah menyimpang dari tujuan penciptaannya sebagai insan pengelola Bumi. Mengubah cara pandang dan perilaku manusia terhadap lingkungan tentu tidak mudah. Beberapa perilaku yang harus diubah untuk menangani krisis lingkungan dunia modern, yaitu:

a. Bahwa alam semata-mata untuk manusia sehingga boleh sewenang-wenang.

b. Bahwa manusia adalah sumber semua tata nilai yang ada (antroposentris).

c. Bahwa kesuksesan hanya diukur dari materi.

d. Bahwa sumber daya materi dan energi tidak terbatas.

e. Bahwa produksi dan konsumsi barang dapat meningkat terus tanpa batas.

f. Bahwa tidak perlu beradaptasi dengan lingkungan karena ada sains - teknologi.

Dengan demikian, dapatlah disebutkan bahwa perilaku, etika atau akhlak menjadi opsi solusi dalam konservasi lingkungan: air, tanah, udara. Manusia perlu beretika terhadap air, tanah, udara karena hidup manusia bergantung kepadanya. Air misalnya, biasa digunakan untuk bebersih dan minum. Tubuh manusia $65-75 \%$ terdiri atas air. Tidak seperti planet lainnya, dua pertiga muka Bumi ini ditutupi air (danau, waduk, sungai, laut). Ada yang digunakan untuk pembangkit listrik, transportasi, rekreasi, olah raga, perikanan, dan sumber air baku untuk air minum.

Air itu sumber hidup (sakral). Tingginya kesakralan air tampak dari ungkapan ini: tirtha nirmala, tirtha kamandalu, amrta njiwani (Sansekerta), maaul hayat (Arab), nectar-ambrosia (Yunani), the elixir of life, the liquid of life (Inggris), air suci (Indonesia). Tapi jauh sebelum ini, pada masa silam nilai spiritual atau pendewaan air telah luas dikenal. Di Prancis, di dekat Sungai Seine, ada kuil suci untuk Dewa Sequana. Sungai Marne asal-usul namanya dari Matrona yang artinya Dewi Ibu. Cikal nama Sungai Thames di Inggris ialah Tamesa atau Tamesis yang terkait 
dengan makna ketuhanan. Sungai Nil di Mesir tak lepas dari Fir'aun dan Nabi Musa. Adapun Sungai Amazon di belantara Brasil, Amerika Latin dihuni suku pemulia dewa-dewi. Sungai Euphrates dan Tigris di Irak dihormati kaum Babylonia dan Mesopotamia.

Dalam agama Hindhu air digunakan untuk bebersih setiap hari, sebagai bagian dari kewajiban. Lihatlah betapa ritus Kumbh Mela dipadati 30 juta orang. Gangga, sungai tempat ritus itu bahkan dinobatkan dengan 108 nama-nama indah. Tempat sucinya, yaitu kuil banyak dibuat di dekat sumber air, mata air atau sungai. Berikut adalah komentar Dr. F.C. Harrison yang dikutip Shiva. "Menurut fakta yang janggal, yang belum pernah dijelaskan secara memuaskan, adalah begitu cepatnya (tiga sampai lima jam) kuman kolera mati di Sungai Gangga. Ketika seseorang mengingat banyaknya kotoran yang dibuang para penduduk, yang sering merupakan penderita kolera, dan ribuan penduduk yang mencebur ke sungai, tampak sungguh luar biasa bahwa kepercayaan orang Hindhu, bahwa sungai ini memiliki air yang murni dan tidak bisa tercemar dan mereka bisa dengan aman meminum airnya dan mandi di dalamnya, bisa dibuktikan dengan alat penelitian bakteriologi modern". Tak heran, lanjut Shiva, masyarakat India begitu sayang pada Sungai Gangga dan sungai-sungai lainnya dan percaya jika sungai-sungai itu memiliki kekuatan misterius." Bagaimana di Indonesia? Bagaimana Citarum?

Di Bali, pemeluk Hindu tak bisa dipisahkan dari air. Di setiap tempat dan masa perayaan hari agama selalu saja disertakan air. Air ini, bagi penganut Hindu di Pulau Dewata adalah air suci yang dinamai tirta. Selain dikibas-kibaskan atau dipercikkan ke kepala peserta ritual oleh pemimpin prosesi (Bali: pedanda, mangku) air itu pun didekatkan ke mulut sambil dicicipi. Simbol air sebagai sumber hidup. Luar biasa. Dalam Agama Kristen-Katolik, air digunakan dalam upacara baptis. Lokasi baptis dan gereja biasanya dipilih dekat dengan mata air atau ada sumber air. Dalam agama Budha, air dilibatkan dalam proses pemakaman. Yahudi juga menggunakan air dalam ritual mandi atau Mikveh khususnya pada hari Jumat atau sebelum perayaan besar. Perempuan Yahudi juga wajib Mikveh sebelum menikah dan setelah melahirkan dan menstruasi.

Dalam Islam air dinyatakan sebagai sumber segala yang hidup (Al Anbiyya ayat 30: "dan dari airlah Kami jadikan segala sesuatu yang hidup"). Air dibutuhkan dari hari ke hari, jam ke jam. Intensitas kata yang terkait dengan air itu mencapai 63 kali, tulis Othman dan Doi dalam jurnal Thought and Scientific Creativity di bawah judul Islamic Principles of Environment and Development. Tentu saja air di atas bisa juga ditafsirkan sebagai komponen utama dalam siklus hidrologi yang melestarikan fungsi Bumi dan menguatkan eksistensi kekhalifahan manusia atas makhluk lain, biotik dan abiotik. Esensi khalifah ialah memimpin, yakni pemimpin yang melayani, yang dalam istilah Danah - Zohar disebut the servant leader (pemimpin pengabdi). Artinya juga, manusia harus melayani lingkungan dengan cara beretika mulia, akhlak karimah.

Komponen lingkungan berikutnya adalah tanah. Tanah (debu) pun penting bagi manusia; bagi muslim digunakan untuk tayyamum ketika tidak ada air atau saat sakit. Dalam ritual wudhu dan tayyamum itu besarlah peran air dan tanah (debu) sehingga 
tercelalah apabila manusia mencemari airnya dan menggurunkan tanahnya dengan cara membabat hutan. Oleh sebab itu, perusak lingkungan bisa disebut teroris karena meneror kenyamanan hidup manusia, hewan dan tumbuhan. Para pembalak liar (illegal logging), sebagai misal, harus dihukum berat agar memberikan efek jera bagi pelaku lainnya. Dampak teroris lingkungan disebut dalam ar-Ruum: 41. Ayat ini mengulas kerusakan lingkungan akibat ulah manusia, secara perorangan maupun kelompok, dalam lingkup kecil maupun besar. Akibatnya, Bumi disesaki sampah, limbah cair, dan polutan udara.

Mengapa etika menjadi esensial dalam memberikan solusi bagi lingkungan (air, tanah, udara)? Karena manusia sulit dipisahkan dari planet Bumi dan tak mungkin bisa hidup di planet lain tanpa alat bantu oksigen. Jangankan di planet lain yang berada di lain tatasurya dan lain galaksi, di planet Mars saja belum ada manusia yang mampu hidup dengan alat-alat bantu sekalipun. Artinya, manusia memang dijadikan khalifah di Bumi dan dari planet inilah manusia harus mengabdi kepada Tuhannya. Salah satu caranya, bisa dengan Pendidikan Lingkungan Hidup (PLH) yang lebih menitikberatkan pada aspek afektif-psikomotorik, bukan kognitifnya.

Sekali lagi, esensi konservasi lingkungan (air, tanah, udara) tak lain adalah etika terhadap lingkungan. Alasan terkuatnya, manusia berasal dari tanah dan akan kembali menjadi tanah. Sumber makanan manusia, hewan dan tumbuhan, pun tak lepas dari tanah. Bahkan Bumi dideklarasikan sebagai tempat mengabdi bagi manusia. Begitu bernilainya Bumi, tak kurang dari 461 kali Allah menyebutnya di dalam Qur'an. Uniknya lagi, Bumi ini kaya tanaman. Hamparan hutan dan kebun berbunga aneka warna diibaratkan dengan pakaian indah dan harum bagi Bumi (arRahman: 11-12). Qur'an pun menjelaskan fungsi estetika dan dekoratif tanaman bagi manusia. Keindahannya tak hanya secara visual tetapi lebih dari itu, mekanisme reproduksinya berpasangan secara seksologi (ar-Ra'du: 3), ada jantan, ada betina.

Selanjutnya ialah tentang keragaman (biodiversitas) binatang atau ternak (berkaki dua: unggas; berkaki empat: sapi, kuda, kerbau, unta, domba) yang menjadi ornamen Bumi. Ada yang digunakan untuk kendaraan, penggembala, dimakan atau dinikmati keindahannya. Binatang yang 'menjijikkan' seperti ular dan cacing yang berjalan dengan perutnya pun diciptakan Allah (an-Nuur: 45).Variasi cara berbiaknya (reproduksi) pun mencirikan keagungan Penciptanya.

Oleh sebab itu, demi mengurangi krisis air dan agar bencana lingkungan tidak meluas wajiblah kita mengelola sumber daya alam, sumber daya manusia dan sumber daya moral (etika, akhlak) agar kita (manusia) tidak berubah dari the best (terbaik, yakni bani Adam) menjadi the beast (buas, iblis). * 


\section{Daftar Pustaka}

Al Qur'an al Karim.

1. Cahyana, G., H., PDAM Bangkrut? Awas Perang Air, Sahara Golden Press, 2004.

2. Mangunjaya, F., Konservasi Alam Dalam Islam, Yayasan Obor Indonesia, 2005.

3. Purwanto, A., Ayat-Ayat Semesta: Sisi-sisi Al Quran Yang Terlupakan, Mizan, 2008.

4. Shiva, Vandhana, Water Wars, Insist Press - Walhi, 2003.

5. Sunardi, Ph.D., Perlindungan Lingkungan: Sebuah Perspektif - Spiritualitas Islam, PSM Ilmu Lingkungan Univ. Padjadjaran, 2008.

Makalah ini disampaikan dalam Seminar Nasional: The Smiling Earth, Jurusan Teknik Lingkungan, Universitas Kebangsaan, Bandung, Sabtu, 28 Mei 2011.

Atas permintaan wartawan Bandung Ekspres, artikel ini diterbitkan di Bandung Ekspress, 3 Juni 2011. 